\section{Pacific Northwest}

National Laboratory

Operated by Battelle for the

U.S. Department of Energy

\title{
FY05 SWIR-CRDS Summary Report
}

\author{
R. M. Williams \\ T. L. Stewart \\ J. S. Thompson \\ B. J. Tweedy \\ E. C. Golovich
}

December 2005

Prepared for the U.S. Department of Energy

under Contract DE-AC05-76RL01830 


\title{
DISCLAIMER
}

This report was prepared as an account of work sponsored by an agency of the United States Government. Neither the United States Government nor any agency thereof, nor Battelle Memorial Institute, nor any of their employees, makes any warranty, express or implied, or assumes any legal liability or responsibility for the accuracy, completeness, or usefulness of any information, apparatus, product, or process disclosed, or represents that its use would not infringe privately owned rights. Reference herein to any specific commercial product, process, or service by trade name, trademark, manufacturer, or otherwise does not necessarily constitute or imply its endorsement, recommendation, or favoring by the United States Government or any agency thereof, or Battelle Memorial Institute. The views and opinions of authors expressed herein do not necessarily state or reflect those of the United States Government or any agency thereof.

\author{
PACIFIC NORTHWEST NATIONAL LABORATORY \\ operated by \\ BATTELLE \\ for the \\ UNITED STATES DEPARTMENT OF ENERGY \\ under Contract DE-AC05-76RL01830
}

Printed in the United States of America
Available to DOE and DOE contractors from the Office of Scientific and Technical Information,
P.O. Box 62, Oak Ridge, TN 37831-0062;
ph: (865) 576-8401
fax: $(865) 576-5728$
email: reports@adonis.osti.gov

\footnotetext{
Available to the public from the National Technical Information Service, U.S. Department of Commerce, 5285 Port Royal Rd., Springfield, VA 22161 ph: (800) 553-6847 fax: $(703) 605-6900$ email: orders@ntis.fedworld.gov online ordering: http://www.ntis.gov/ordering.htm
}

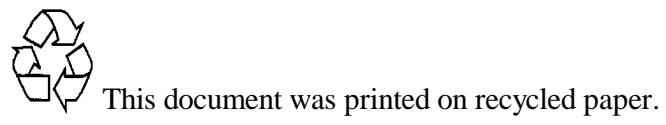




\title{
FY05 SWIR-CRDS Summary Report
}

\author{
R. M. Williams \\ J. S. Thompson \\ E. C. Golovich \\ T. L. Stewart \\ B. J. Tweedy
}

December 2005

Prepared for the U.S. Department of Energy under Contract DE-AC05-76RL01830

Pacific Northwest National Laboratory

Richland, Washington 99352 



\section{Summary}

During FY05 PNNL continued to improve and field test its Shortwave Infrared (SWIR) Cavity Ringdown Spectrometer (CRDS). Major accomplishments include a significant reduction in size and weight of the instrument ( $\sim 50 \%$ reduction), and participation in two field campaigns. The first of these two field tests was conducted at DOE's Hanford site during the month of May which involved the release of ammonia. The second test was conducted at the Nevada Test Site during the Shrike Tests in July. During both of these tests the instrument performed as expected and was able to continuously sample the air and monitor the concentration of ammonia at a data rate of 1 absolute concentration point per second with a limit of detection (LOD) of approximately $500 \mathrm{ppb}_{\mathrm{v}}$. During the Shrike Tests the SWIR-CRDS instrument ran continuously in the desert environment for 4 days without the need for adjustment. In an attempt to increase the ultimate utility of Cavity Enhanced Sensing (CES) for monitoring more unique proliferation signatures, testing of a new broad-band CES approach was initiated. This was the final test of this instrument, no further development or fielding of this instrument has been funded. 


\section{Contents}

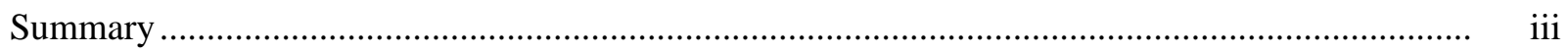

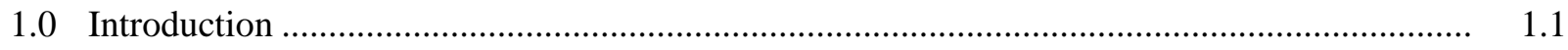

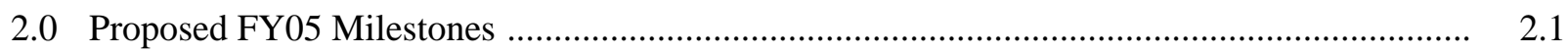

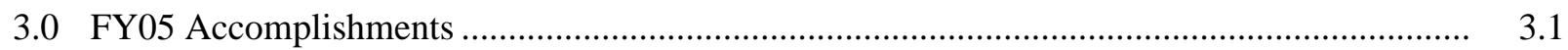

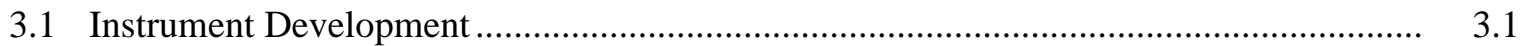

3.2 Hanford Town Site Ammonia Release ............................................................... 3.2

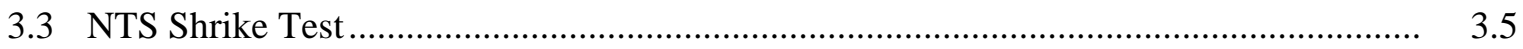

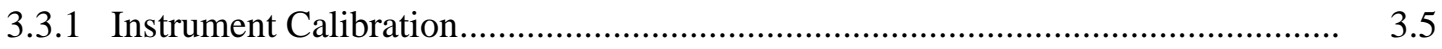

3.3.2 Instrument Deployment ............................................................................ 3.6

3.3.3 SWIR-CRDS Ammonia Monitoring during Shrike ......................................... 3.7

3.4 Broad-band Cavity Enhanced Sensing ..................................................................... 3.10

3.4.1 Introduction to BB-CES .................................................................... $\quad 3.10$

3.4.2 Technical Approach to BB-CES …................................................................. 3.11

3.4.3 Initial Laboratory Measurements of BB-CES …................................................. 3.13

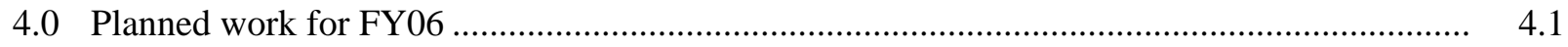

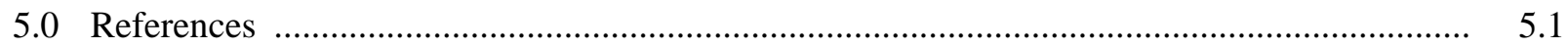




\section{Figures}

3.1 The photograph on the left depicts the instrument as it was during FY03 \& 04, while the image on the right is the current instrument configuration.

3.2 Photograph of the current instrument configuration including the small AC unit and vacuum pump mounted on the mobile utility cart.

3.3 Photograph of the SWIR-CRDS instrument at the Hanford Town Site in May, 2005. The instrument is being adjusted in the field prior to ammonia release experiments. The portable plume generator is visible in the upper left corner of the photograph (vertical 6" white PVC pipe on tripod) ...... 3.3

3.4 Results from ammonia release experiments at the Hanford Town Site during May of 2005. Rapid variations in observed ammonia levels are due to wind speed and direction variability. The . operating pressure of the SWIR-CRDS during these tests was 485 Torr

3.5 SWIR-CRDS instrument response curve for ammonia in the range of $100 \mathrm{ppb}_{\mathrm{v}}-50 \mathrm{ppm}_{\mathrm{v}}$. Based on these results actual measured concentrations are scaled by 2.10 to reflect the true amount ..... 3.5

3.6 Schematic representation of the placement of PNNL's sensors during the Shrike Campaign at NTS....

3.7 Photograph of the CRDS instrument during the Shrike Campaign at NPTEC

3.8 Snapshot of the logged data from the SWIR-CRDS instrument during the time on July $13^{\text {th }}$ when ammonia was released. No additional data processing has been done to the data. The "stair-step" decrease in the release rate of ammonia is clearly visible as well as the variability in wind direction which causes the monitored signal to drop

3.9 Data from NPTEC's PID sensor placed next to PNNL's CRDS instrument. The level of agreement between the CRDS and PID sensors is excellent. The PID is not capable of discerning what the actual chemical is that is being registered, only inferred based on the chemical released ammonia .. was released

3.10 Plot of the baseline variance of the SWIR-CRDS just prior to the ammonia release on ......

3.11 Broad band cavity enhanced sensing concept; a) depiction of the laser source, sampling cavity and spectrometer, b) schematic showing mode overlap between laser and cavity and c) simulated spectra of sample and empty cavity..... 
3.12 Taken from ref. (1) showing spectrum of fsec laser light transmitted through an empty cavity (a), a cavity with acetylene sample (b) and the resulting absorbance spectrum (c) computer from (a) and (b).

3.13 PNNL's BB-CES laboratory demonstration experiment. The cavity length is such that every other mode from the fsec laser is resonant.

3.14 Cavity transmission spectra recorded as the absolute cavity length is adjusted away from the optimum for coupling to the output of a $75.5 \mathrm{MHz}$ mode-locked laser. 0 microns displacement corresponds to a fixed cavity length of $99.0 \mathrm{~cm}$ 



\subsection{Introduction}

PNNL's cavity ringdown spectrometer is a fieldable "point sensor" based upon an optical absorption technique that is capable of autonomous, real-time chemical monitoring of various trace atmospheric species. During its three year development cycle, the instrument completed six field demonstrations, during which the instrument performed as expected. A thorough description of the operating principle behind cavity ringdown (CRD) spectroscopy can be found in the FY03 \& FY 04 summary reports, only a brief description will be given here (Williams et al. 2003 and Williams et al. 2004).

The basic objective behind all optical absorption spectrometers is to produce an instrument that is capable of detecting a minute change in the detected light intensity after that light passes through a sample. Typically the wavelength of the light is scanned such that an absorption feature from the species of interest can be identified. This observed absorbance is linearly proportional to the absolute concentration of the chemical via the Beer-Lambert relation. Therefore to detect trace levels of the analyte of interest it is necessary to be able to detect very weak absorption signals. The practical difficulty in extracting these weak features is that they are often masked by other forms of noise such as optical fringing, baseline drift or simply an excess of random noise. Cavity ringdown spectroscopy is a technique in which these external noise sources have a reduced impact on the overall signal to noise. Rather than making a measurement of the light intensity after passing through a sample, CRDS relies on a measurement of loss per round trip within an optical cavity made up of two highly reflective mirrors. Loss is measured by recording the decay rate of light which "leaks" out of the cavity after the incident light is switched off. Cavity loss (and decay rate) increase as chemicals enter the cavity which absorb the laser light at that particular wavelength. By measuring the cavity decay rate (i.e., ringdown time constant), rather than the overall light intensity, CRDS is less sensitive to laser intensity noise and optical fringing than conventional spectroscopic techniques. Because of this, PNNL's CRDS instrument is capable of observing absorbance signals on the order of $5 \times 10^{-7}$. Factoring in the physical pathlength of the cavity $(50 \mathrm{~cm}$ ) and the number of ringdown events observed (and averaged) per second (300) a Noise Equivalent Absorption Sensitivity (NEAS) of $5 \times 10^{-10} \mathrm{~cm}^{-1} / \sqrt{ } \mathrm{Hz}$ can be derived.

Cavity ringdown spectroscopy has been widely accepted in the scientific community as a technique for making very sensitive absorption measurements. This is due to its relative ease of setting up an instrument and wide applicability (e.g., gaseous, solid and liquid samples). Despite this very few CRDS experiments have made the transition from the laboratory environment to portable field units. PNNL's CRDS instrument is among the first of such units and valuable insight and experience has been gained transitioning this technique to the field. In order to field this instrument in a timely manner a decision was made early in the project that the operating wavelength would be shortwave infrared (SWIR), between 1.2 and 1.6 microns. This region was selected because of the wide availability of commercial laser sources and detectors that are both rugged and have the high quality needed for CRDS. Most molecular species have vibrational absorption features in this part of the infrared spectrum, however these absorption features are generally much weaker than those further in the mid- or long-wave infrared. This reduction in absorption strength directly impacts the detection limits of the instruments. Therefore PNNL's SWIR-CRDS instrument has a lower limit of detection for many simple molecules in the $\mathrm{ppb}_{\mathrm{v}}$ to $\mathrm{ppm}_{\mathrm{v}}$ range. A similar instrument operating in the mid- to long-wave infrared should have a $\mathrm{ppt}_{\mathrm{v}}$ to $\mathrm{ppb}_{\mathrm{v}}$ 
limit of detection (LOD). In fact PNNL is developing such cavity enhanced sensors using quantum cascade lasers.

Despite the higher detection limit, PNNL's SWIR-CRDS instrument was designed to fill a technology gap in the wide range of chemical sensors that are currently available to the end-user. Primary importance was placed on creating an instrument that was automated and produced results in near realtime. Using software control, PNNL's instrument can be operated indefinitely without user input (after the initial setup). This was demonstrated in FY05 after completing a 28 day laboratory trial run. Real time chemical concentration logging was achieved by flowing large volumes of sample through the system (> 5 slpm; standard liters per minute) and implementing a rapid "on/off" resonance measurement routine. Using this approach we achieved absolute chemical concentration logging at a rate of 1 measurement per second.

A primary objective for FY05 was to maintain this capability while at the same time reducing the overall size and weight of the instrument (making it more attractive as a practical sensor). Additionally further field testing was important as it provided further validation of the CRDS technique as a robust approach to real-time chemical sensing for non-proliferation applications. These will be described in more detail within the body of this summary report. 



\subsection{Proposed FY05 Milestones}

\section{PL211I-Subtask 2.b. SWIR CES [\$225k Lab]}

1) Enhance the performance of PNNL's SWIR cavity enhanced sensing technique to allow for the broadest possible application to proliferation detection. This will utilize a broadband laser source rather than a narrow linewidth laser in our sensing approach to facilitate detection of proliferation signature molecules with broader optical absorption features.

2) Reconfigure PNNL's SWIR-CRDS field experiment for maximum performance in a smaller more portable package. Participate in the Shrike Field Campaign at NTS during the Summer of '05.

FY2005 SCHEDULED MILESTONES:

7/30/05 Complete the reconfiguration of PNNL's SWIR-CRDS system, perform lab calibration and then participate in Shrike Field Campaign at NTS.

9/30/05 Complete the initial evaluation of broad-band cavity enhanced sensing. 


\subsection{FY05 Accomplishments}

\subsection{Instrument Development}

During FY05 the size and weight of PNNL's CRDS instrument was dramatically reduced. The first fieldable unit consisted of two main components; an optical bench in a shipping crate and an instrument support rack consisting of electronics and gas flow hardware. It was decided that in order to make the instrument more attractive to interested users the overall footprint of the instrument needed to be reduced. An approach was adopted in which the optical bench components and the electronics would be housed in the same portable case. The vacuum pump would be the only item not enclosed in the new case. Additionally some of the gas flow equipment needed to be eliminated from the overall system. The original CRDS instrument incorporated a sophisticated gas flow control system which allowed for an automated transition from sampling ambient air to measuring a calibration gas. Additionally the instrument had, in addition to the standard vacuum pump, a high vacuum turbo molecular pump. It was determined that these items were not as critical to the instrument performance as initially thought therefore they were removed from the smaller instrument. The main components remaining in the system included: the laser head and controller, various optics, Fabry-Perot optical cavity, reference gas cell, LCD screen and keyboard, cpu and various power supplies. The vacuum pump is attached through the side of the case by a 3 foot flexible vacuum hose. The inlet consists of a 1/4" OD fitting to which any length of poly tubing can be attached (typically we used $~ 3$ ' of Teflon or polyethylene tubing).

Figure 3.1 shows a comparison on the instrument before and after our size reduction effort. Much of the vacuum hardware removed from the new system can be see at the bottom of the blue instrument support rack.

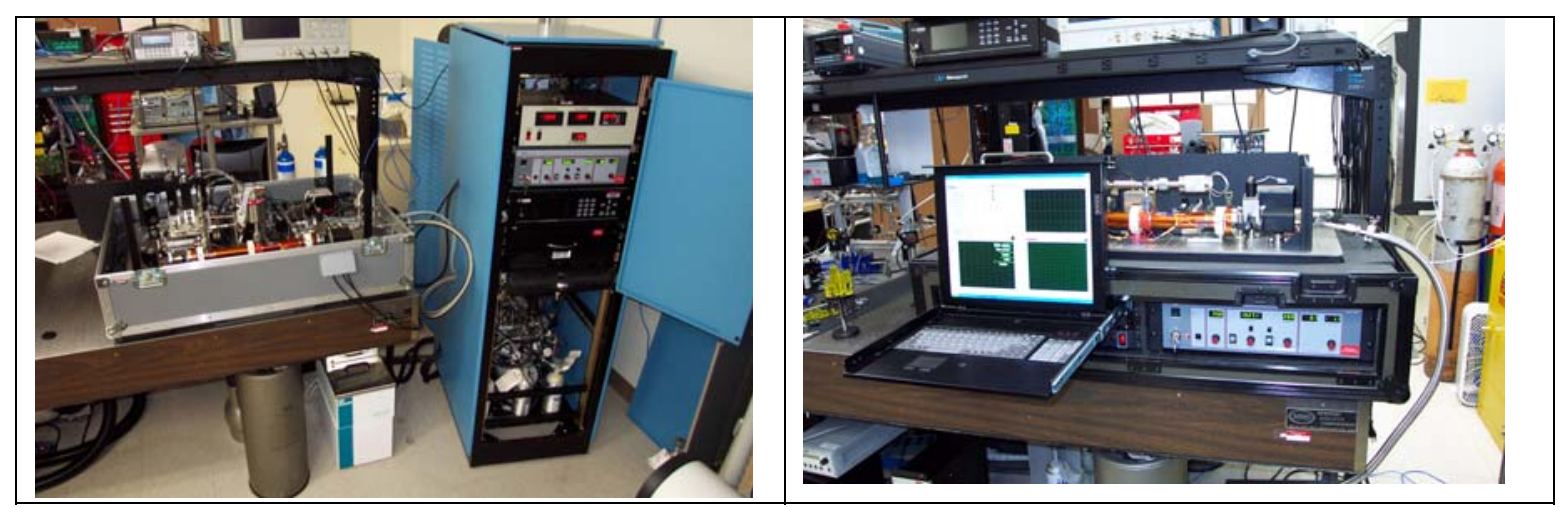

Figure 3.1. The photograph on the left depicts the instrument as it was during FY03 \& FY04, while the image on the right is the current instrument configuration. 
Figure 3.2 is a photograph of the instrument as it is deployed. A sturdy utility cart was found to be a good means of transporting the instrument to various locations during field tests. Large pneumatic tires helped to minimize vibration allowing the instrument to continuously collect data even while being pulled along a gravel road. A small 5000 BTU air conditioner unit was mounted on the cart to supply cool air to the CRDS instrument during hot field tests (like those at NTS in July of 2005). Additionally, a COTS wireless access point was added to the new instrument which allows for wireless communication with the instrument (from a laptop computer) during field tests. The range of this system was found to be approximately $1 \mathrm{~km}$.

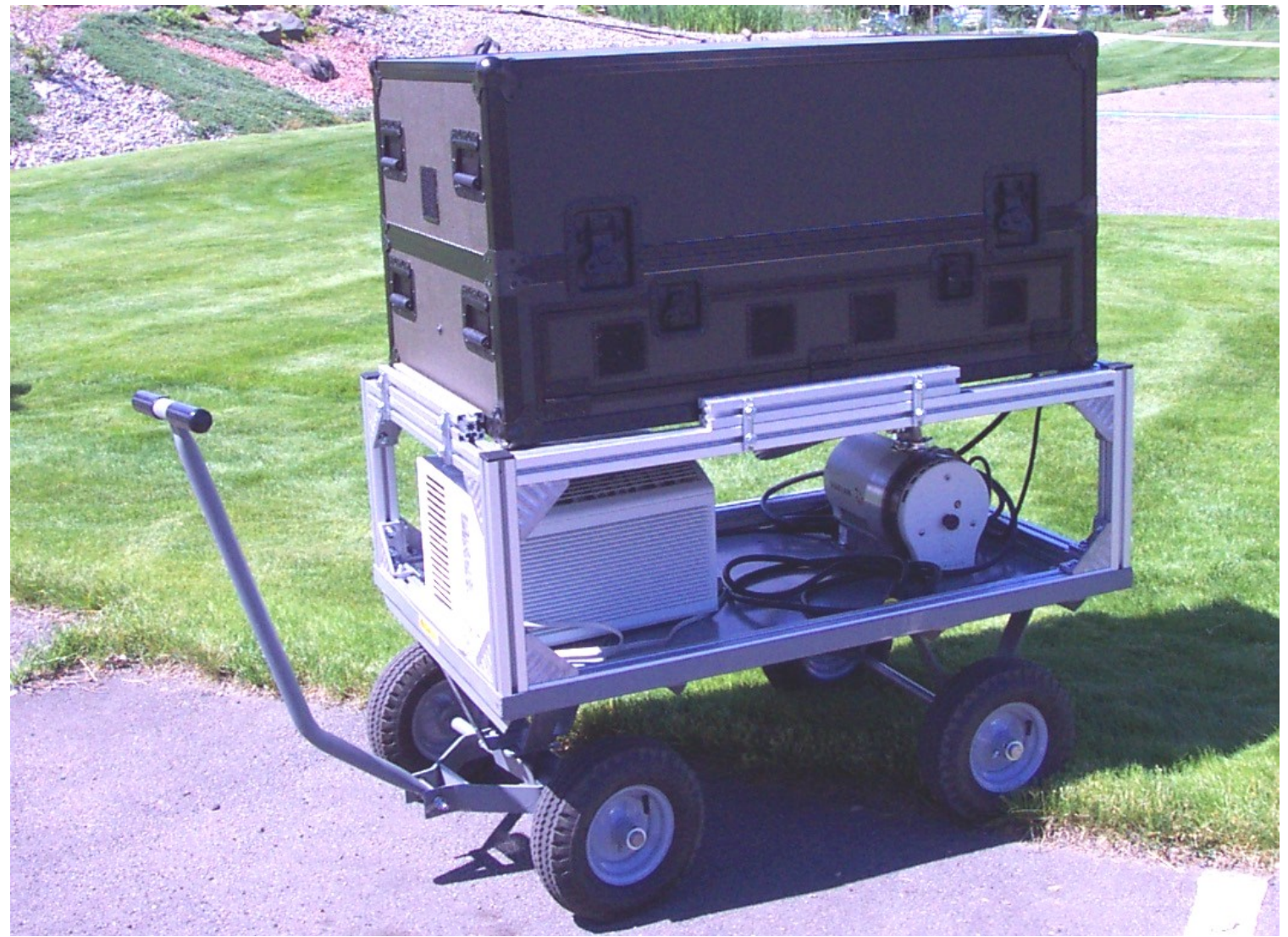

Figure 3.2. Photograph of the current instrument configuration including the small AC unit and vacuum pump mounted on the mobile utility cart.

\subsection{Hanford Town Site Ammonia Release}

During the week of May $16^{\text {th }}, 2005$ the SWIR-CRDS instrument participated in a joint chemical release experiment at the Hanford Town site on DOE's Hanford reserve just North of PNNL. 
Prior to this field test the instrument was configured to continuously monitor for ammonia (previously it had been setup for the detection of HF). The appropriate laser and optics were installed and the system was fully tested in the laboratory prior to field deployment. As outlined in PNNL's FY04 annual report the on/off resonance approach was used to monitor ammonia. This approach allows for real-time chemical monitoring using an absorption feature detected in a reference gas cell contained in the instrument. In this case an ammonia feature at a wavelength of $1531.68 \mathrm{~nm}$ was used as it is clear from background interferents. During the week long test the instrument was powered from a gasoline powered generator. Two electronic components failed during the tests: a data acquisition board in the computer and a valve actuator. These components were quickly replaced in the field and testing resumed.

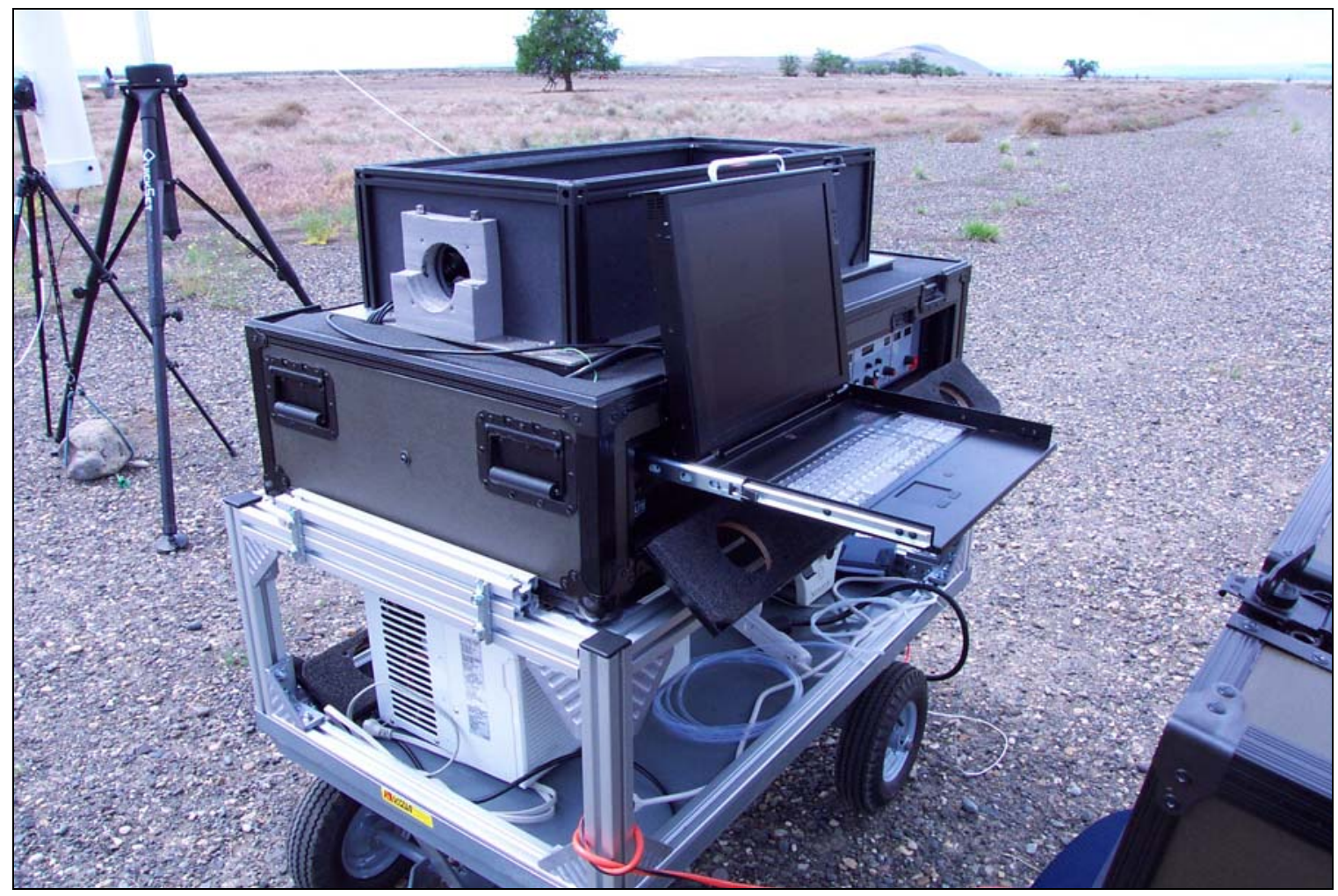

Figure 3.3. Photograph of the SWIR-CRDS instrument at the Hanford Town Site in May, 2005. The instrument is being adjusted in the field prior to ammonia release experiments. The portable plume generator is visible in the upper left corner of the photograph (vertical 6" white PVC pipe on tripod).

The major goal of this field test was to verify the baseline performance of the instrument in an actual field environment. After the hardware problems were corrected the instrument succeeded in detecting and monitoring ammonia released from the source. Dilute ammonia $\left(\sim 100 \mathrm{ppm}_{\mathrm{v}}\right)$ was released from the 6" OD stack at a rate of $33 \mathrm{cfm}$. Because the source was already quite dilute the inlet sampling line for the SWIR-CRDS was kept within 2 meters downwind of the stack. Figure 3.4 shows the release results from May $23^{\text {rd }}, 2005$. Releases occurred once per hour and lasted for 10 minutes. An interesting result from Figure 3.4 is the rapid variation of the observed ammonia signal. Because the instrument has high throughput and data processing speed, an absolute ammonia concentration is measured approximately 
once per second. Therefore, variations in the observed concentrations due to wind speed and direction are easily observed. From this result it can be concluded that it is important for any kind of point sensor to have a fast response time because of the variability of the wind. It may be that the effluent plume would only be present at the instrument's inlet for very short period of time and then move away. If the instrument's response is too slow this "signal burst" would be lost. It is true however that at much farther distances from the source the plume will expand (and rarify) making it more likely that the sensor's inlet would overlap with the plume.

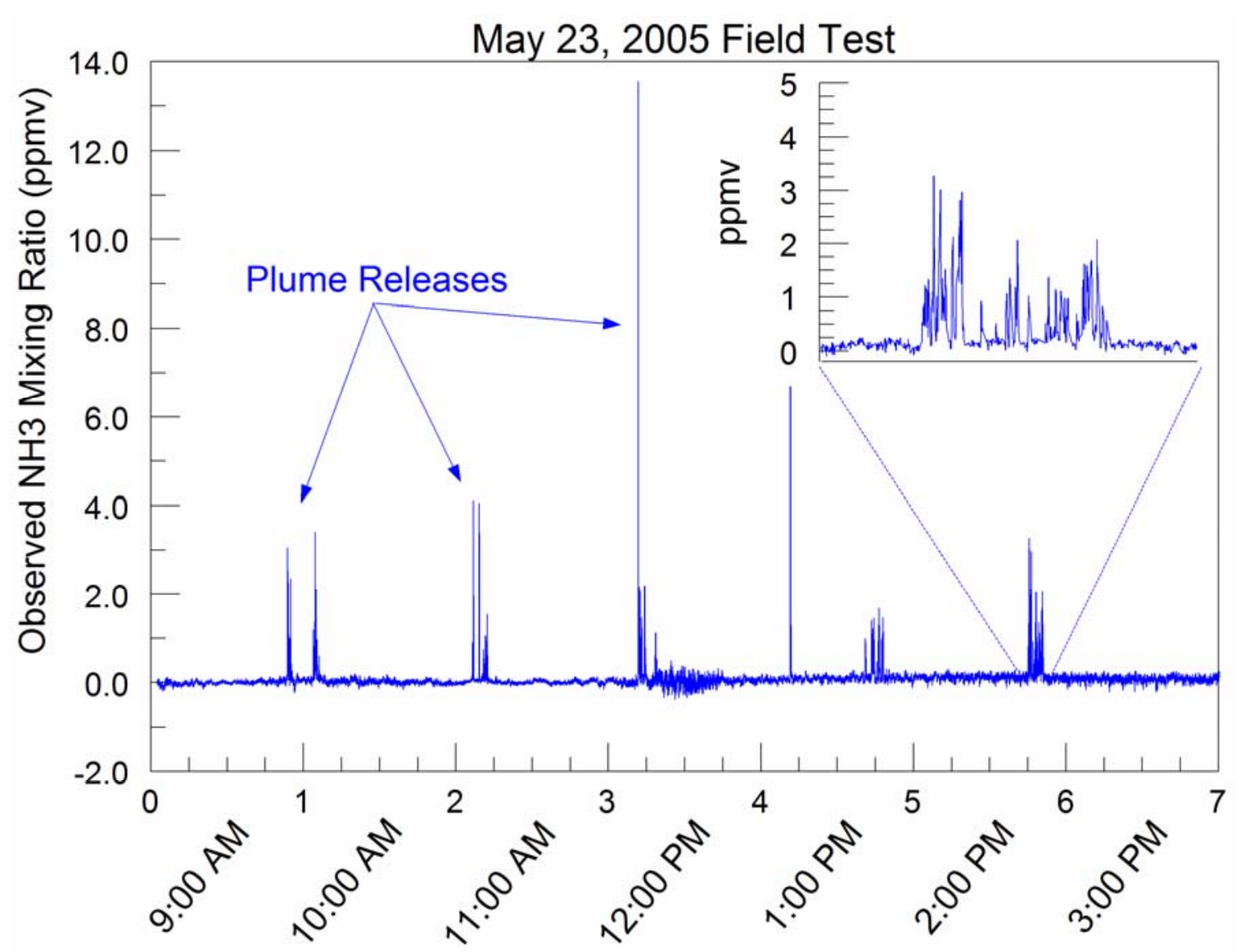

Figure 3.4. Results from ammonia release experiments at the Hanford Town Site during May of 2005. Rapid variations in observed ammonia levels are due to wind speed and direction variability. The operating pressure of the SWIR-CRDS during these tests was 485 Torr. 


\subsection{NTS Shrike Test}

\subsubsection{Instrument Calibration}

Before proceeding with the NTS Shrike field tests a quantitative laboratory instrument response curve was measured. This is accomplished by introducing a known concentration of ammonia at the instruments inlet and measuring its actual response. Many similar measurements are performed while reducing the amount of ammonia delivered to the inlet, in this way the linearity of the response can also be checked. Figure 3.5 shows the result of our laboratory response measurements. Ammonia mixing ratios delivered to the instrument varied from $0.25 \mathrm{ppm}_{\mathrm{v}}$ to $42 \mathrm{ppm}_{\mathrm{v}}$ at a constant cavity pressure of 400 Torr. As can be seen from the plot in Figure 3.5 the system does not measure an amount consistent with that which was introduced. The reason for the reduced response relative to that which was introduced is likely due to ammonia's particular chemical characteristics. Ammonia is a very polar molecule and is one of the strongest gaseous bases, because of this ammonia has a tendency to "stick", or react with, the various surfaces of the instrument. Using these results the measured ammonia concentrations are subsequently scaled by the 2.10 correction factor in order to more accurately reflect the true ambient ammonia levels.

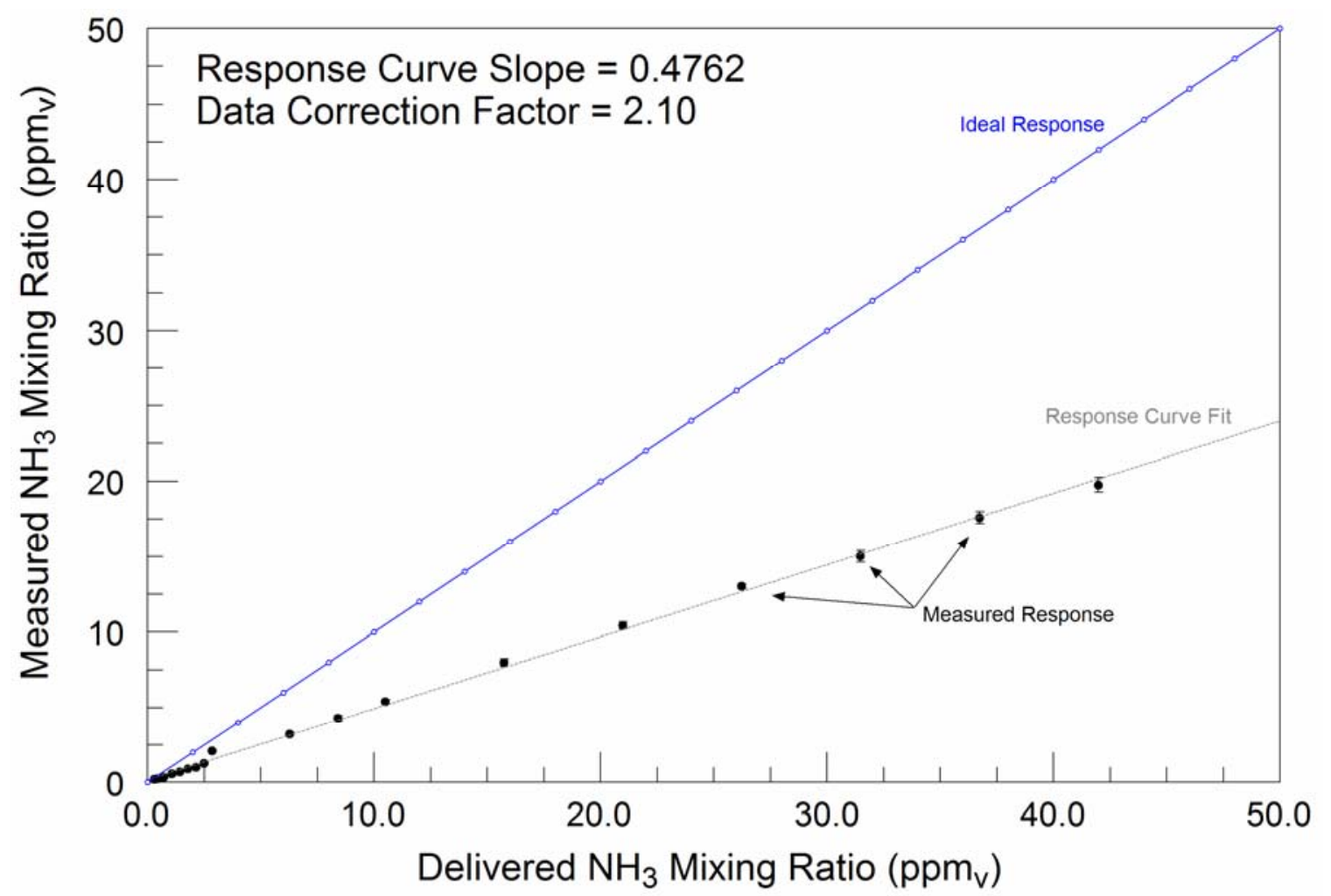

Figure 3.5. SWIR-CRDS instrument response curve for ammonia in the range of $250 \mathrm{ppb}_{\mathrm{v}}-42 \mathrm{ppm}_{\mathrm{v}}$. Based on these results actual measured concentrations are scaled by 2.10 to reflect the true amount. 


\subsubsection{Instrument Deployment}

PNNL's SWIR-CRDS instrument was driven to the Nevada Test Site inside PNNL's Remote Sensing trailer which houses PNNL's FM-DIAL experiment. Initial setup at the Nonproliferation Test and Evaluation Complex (NPTEC) occurred on Monday July $11^{\text {th }}$. Figure 3.6 depicts the position of the SWIR-CRDS instrument relative to the ground-level ammonia release location at the spill center. The instrument was placed 63 meters away from the release point along the $225^{\circ}$ line, a direction relative to the spill center in which the wind commonly blows. Within 30 minutes of off loading from the Remote Sensing trailer the CRDS instrument was properly configured and was continuously logging data. The baseline performance of the instrument had not changed during the transportation to NTS.

Figure 3.7 is a photograph of the instrument during the Shrike Tests. A large portable shade structure was placed over the CRDS instrument to help with cooling in the $110^{\circ} \mathrm{F}$ heat. Additionally the reflective foil blanket which covered the top of the instrument can also be seen. This helped to dramatically reduce absorbed heat by the dark colored instrument crate. The output from the 5000 BTU air conditioner, also mounted on the utility cart, was ducted up to the unit's inlets and helped to maintain an interior temperature of $20-25^{\circ} \mathrm{F}$ cooler than the exterior temperature. A Davis weather station was placed near the instrument (as seen in Figure 3.7). This unit provided real time wind speed and direction data to the data acquisition computer (in addition to exterior temperature).

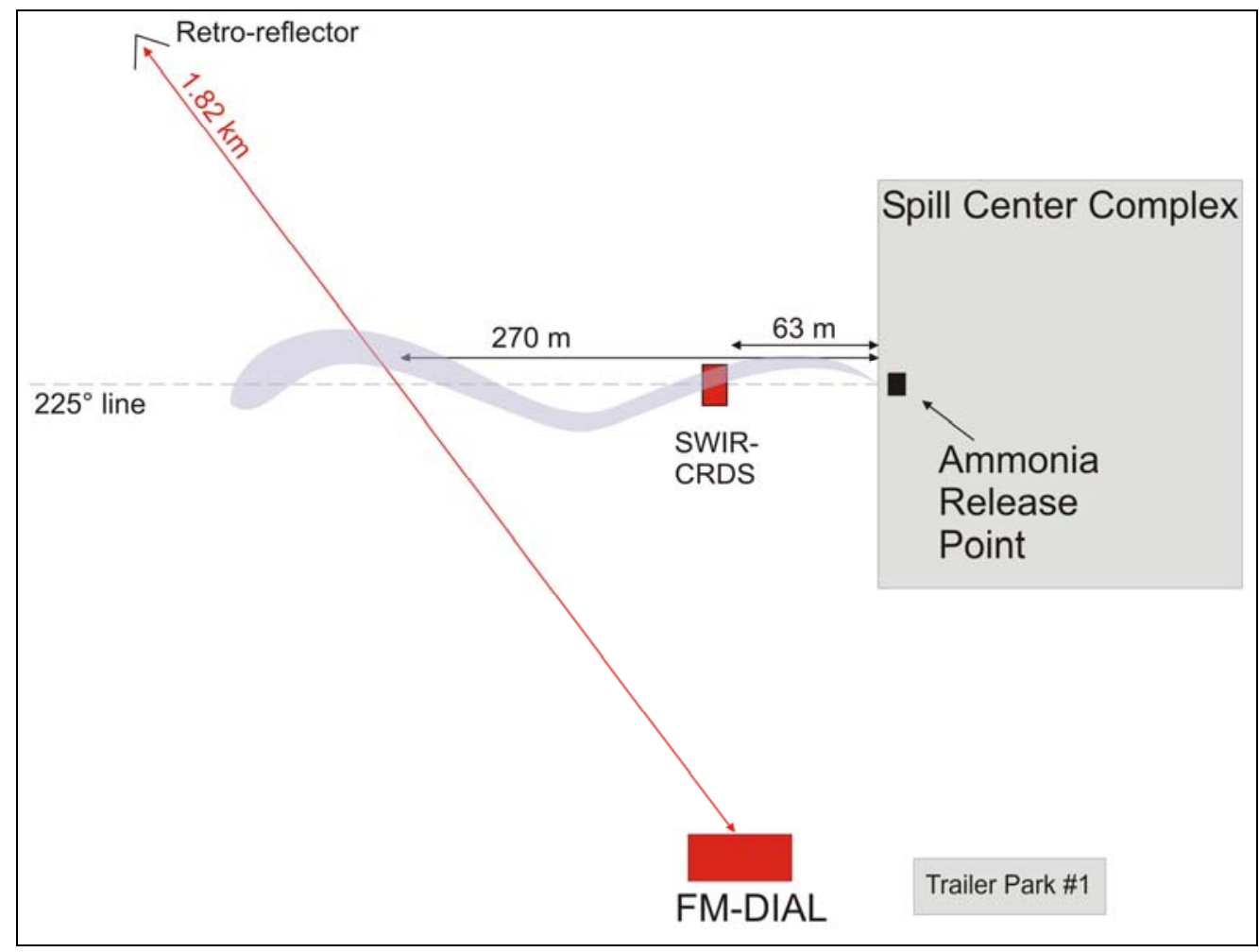

Figure 3.6. Schematic representation of the placement of PNNL's sensors during the Shrike Campaign at NTS. 


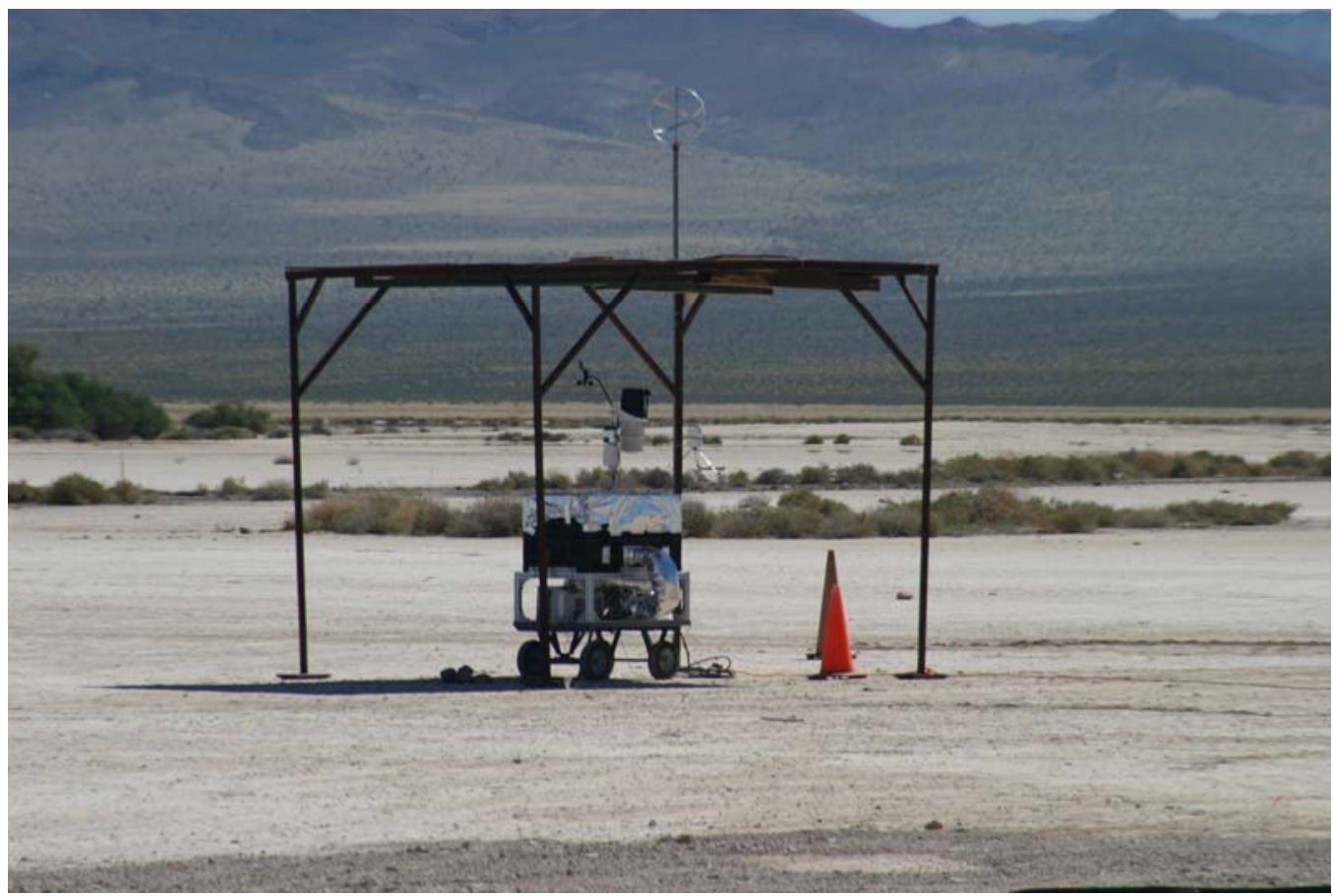

Figure 3.7. Photograph of the CRDS instrument during the Shrike Campaign at NPTEC.

\subsubsection{SWIR-CRDS Ammonia Monitoring during Shrike}

Because of weather related issues only one of the scheduled ammonia releases occurred during the week of July $11^{\text {th }}$. This release occurred during the afternoon of Wednesday, July $13^{\text {th }}$. Figure 3.8 depicts the results from continuously monitoring ammonia during the July $13^{\text {th }}$ release. The data shown is directly from the instrument log, no further data processing was necessary. Ammonia was scheduled to be released four times with a 20 minute duration each time followed by a 40 minute period of no release. During the 20 minute release period the amount of ammonia released was ramped down in the following way: 5 minutes@ $5 \mathrm{Kg} / \mathrm{hr}, 5$ minutes @ $3 \mathrm{Kg} / \mathrm{hr}, 5$ minutes @ $1 \mathrm{Kg} / \mathrm{hr}$ and 5 minutes @ $3 \mathrm{Kg} / \mathrm{hr}$. During the first 20 minute release the wind direction was such the plume missed the instrument inlet except for the last few minutes. During the final 3 releases ammonia was detected during the entire 20 minute cycle. The wind direction was not particularly steady during the afternoon release therefore the plume often missed the inlet causing the observed ammonia levels to decrease to zero. In fact the data shown in Figure 3.8 is actually a good representation of the actual plume evolution during the test. Fortunately we were also able to observe the wind speed and direction during the release. It was noted that ammonia signals were only observed when the wind direction was pointed directly at the instrument relative to the release point with an angular acceptance of $+/-2^{\circ}$. Given that the instrument was 63 meters from the release point this narrow angular acceptance suggests the plume was roughly 5 meters across. It was our intent to move the instrument further away from the release point during subsequent releases in order to push the lower limit of the instrument's detection capabilities, however the weather at NTS did not allow for additional chemical releases. 


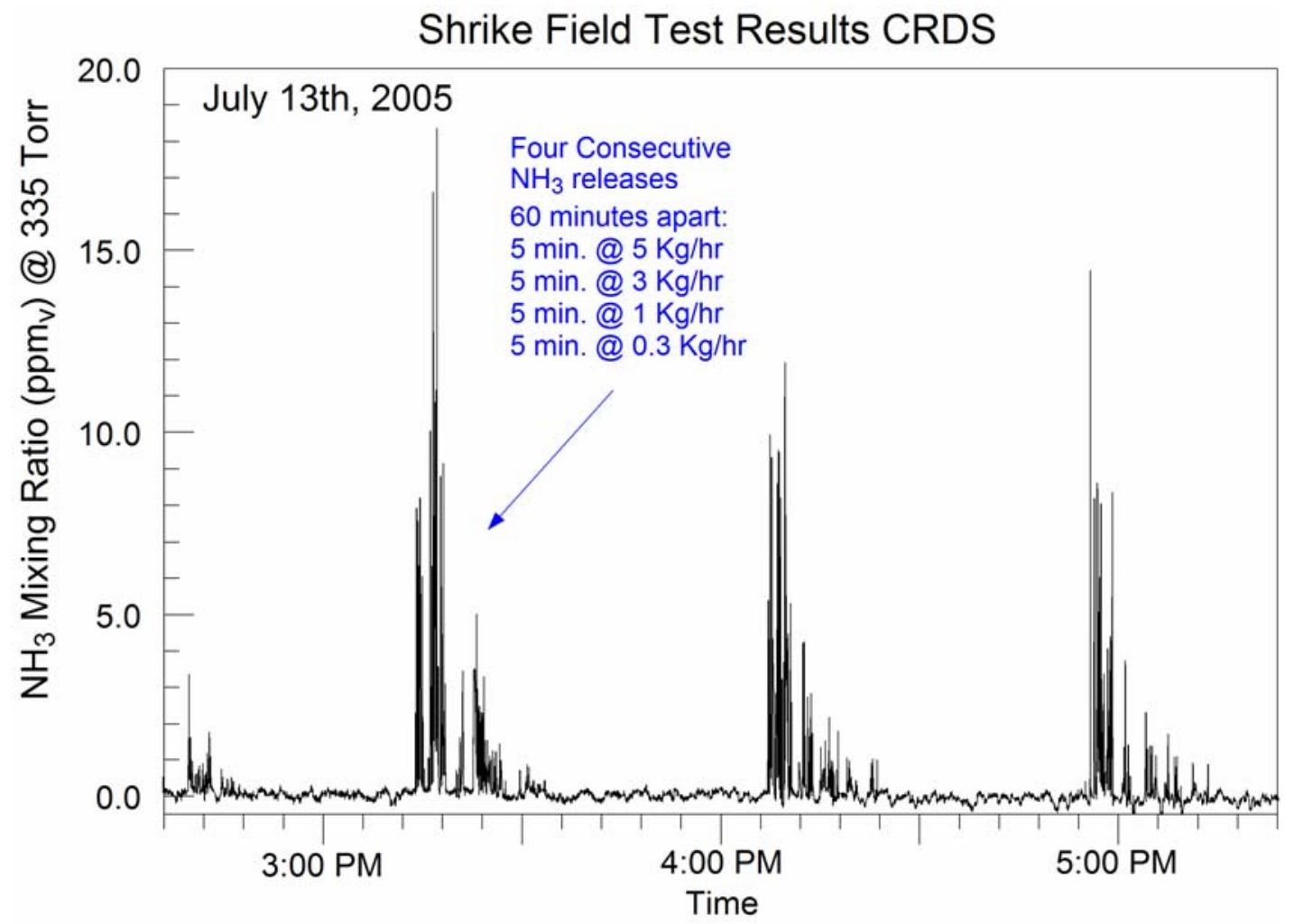

Figure 3.8. Snapshot of the logged data from the SWIR-CRDS instrument during the time on July $13^{\text {th }}$ when ammonia was released. No additional data processing has been done to the data. The "stair-step" decrease in the release rate of ammonia is clearly visible as well as the variability in wind direction which causes the monitored signal to drop to zero.

As part of NPTEC's efforts to provide ground truth instrumentation a photo-ionization detector (PID) instrument was co-located with the SWIR-CRDS instrument. The results from this sensor are shown in Figure 3.9. Comparison of the results in Figures 3.8 and 3.9 show remarkable agreement for both the actual measured ammonia concentration as well as the plume variations. It should be noted that PID sensors, while very sensitive, have very little chemical selectivity. Essentially all chemicals which are ionized by the PID's internal source register as signal. In this case the SWIR-CRDS provides high sensitivity, rapid data rates and response to only a single chemical. 


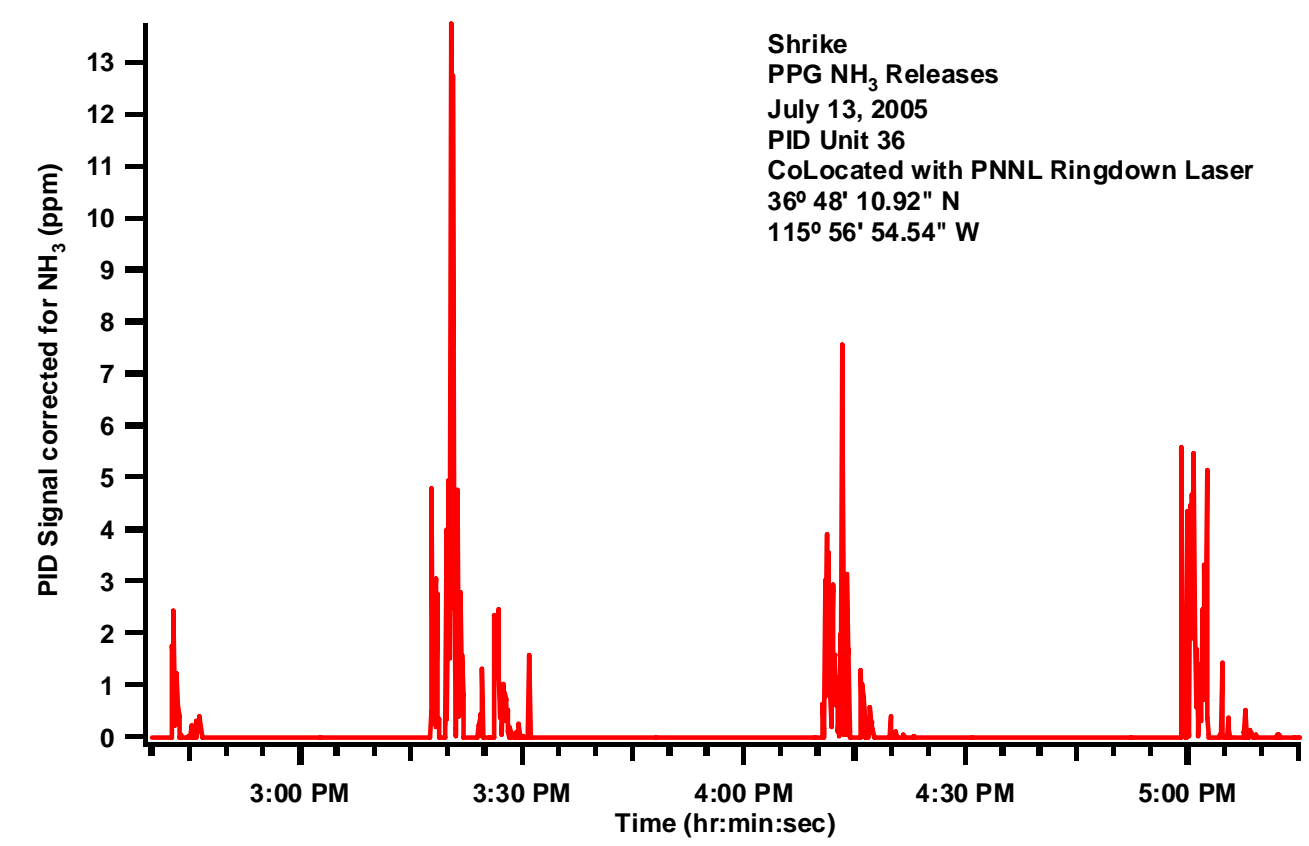

Figure 3.9. Data from NPTEC's PID sensor placed next to PNNL's CRDS instrument. The level of agreement between the CRDS and PID sensors is excellent. The PID is not capable of discerning what the actual chemical is that is being registered, only inferred based on the chemical released from (Williams 2005).

The final piece of noteworthy data from the instrument test at NTS was an evaluation of the instrument's baseline noise performance. This is useful as it provides for a realistic estimate of the instrument's stability and sensitivity in realistic environments. Figure 3.10 depicts $\sim 1.4$ hours worth of baseline measurements taken just prior to the actual chemical release on July $13^{\text {th }}$. The mean baseline value for ammonia is $10.12 \mathrm{ppb}_{\mathrm{v}}$ while the standard deviation is $73.74 \mathrm{ppb}_{\mathrm{v}}$. The exact origin of the slight positive bias in the baseline value is unknown but is relatively small and could possibly be due to the oscillating baseline (rather than a purely random distribution). The standard deviation of $73.74 \mathrm{ppb}_{\mathrm{v}}$ (at a sampling pressure of 335 Torr) corresponds to an ambient concentration of $0.050 \mathrm{mg} / \mathrm{m}^{3}$. 


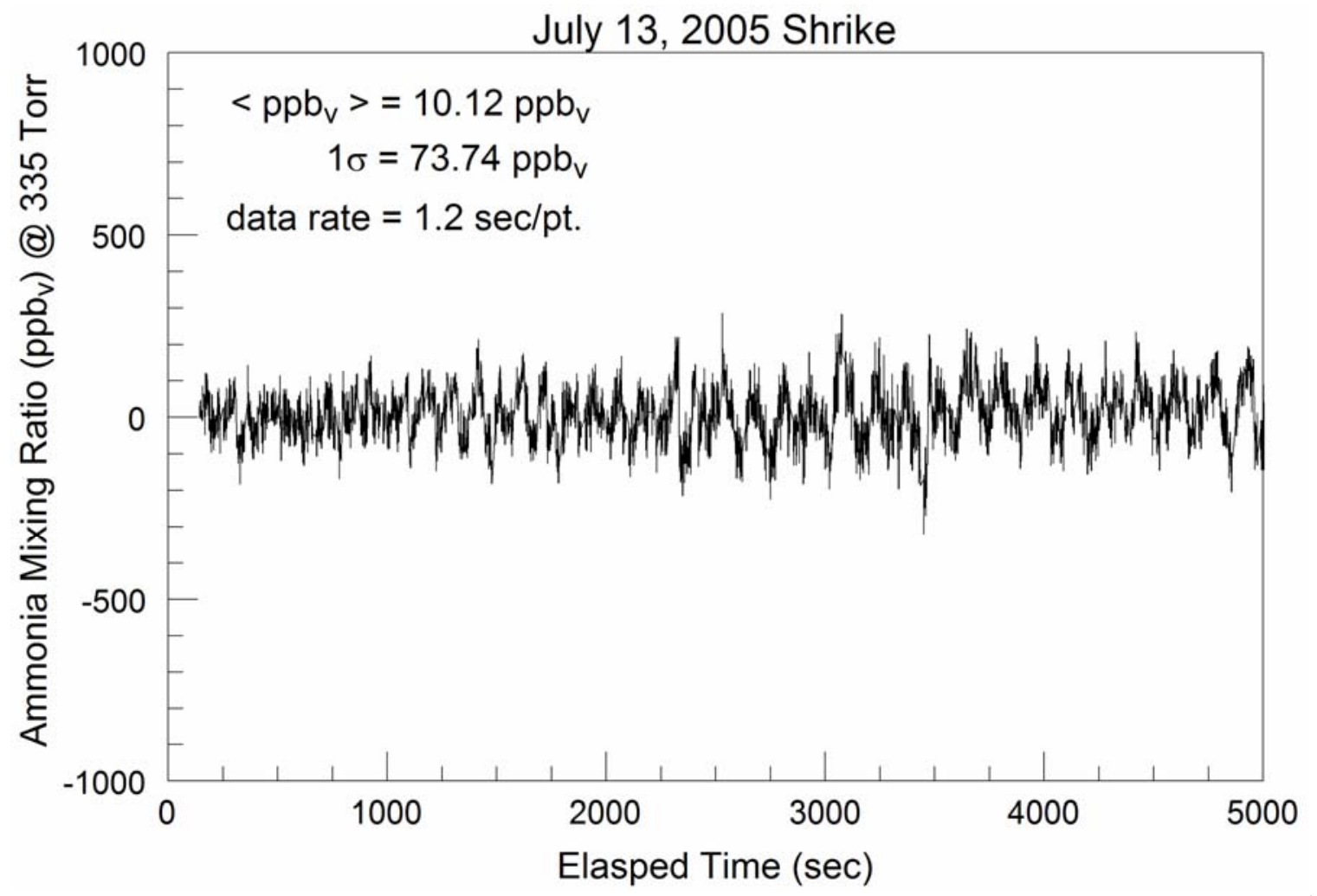

Figure 3.10. Plot of the baseline variance of the SWIR-CRDS just prior to the ammonia release on July $13^{\text {th }}$.

\subsection{Broad-band Cavity Enhanced Sensing}

\subsubsection{Introduction to BB-CES}

In an effort to expand the utility of PNNL's SWIR cavity enhanced point sensor a new approach was explored that would allow for the detection of molecules possessing broad-band infrared absorption features. It is very difficult to use narrow band lasers to successfully detect large molecules with a high degree of confidence. If on the other hand a laser whose output spectrum roughly matches that of the compound of interest then the entire feature (along with potential interferents) can be observed thereby providing a higher degree of confidence in the retrieved data (i.e., less post processing using chemometrics found in some Differential Absorption LIDAR or multi-laser chemical sensors).

The application for which this technology was conceived for is the continuous monitoring of ambient air downwind from a facility suspected of processing spent nuclear fuel. The proposed technology would be well suited to monitor alleged dual-use facilities having a legitimate chemical process which is modified for a short time to chemically extract plutonium and/or uranium from spent fuel rods. An "infield" point sensing approach provides for persistent monitoring which is more likely to observe subtle changes in effluent concentrations indicating a process change within the facility. 
Unlike other laser based point sensors, the proposed instrument would be able to observe broad-band absorption features characteristic of many chemical effluents of the nuclear fuel reprocessing cycle. Traditional laser-based point sensors have not seen the level of accepted use due in some part to their inability to quantifiably detect relevant chemical signatures. These traditional systems are only well suited for the detection of simple molecules which are unfortunately ubiquitous in the environment and not particularly useful in detecting proliferation activities. The system explored here would be capable of quantitative detection of the larger, more complex molecules associated with spent fuel reprocessing (specifically solvent extraction of $\mathrm{Pu}$ and $\mathrm{Ur}$ from dissolved fuel rods). Detection limits of $<1 \mathrm{ppb}_{\mathrm{v}}$ are targeted for samples contained within ambient samples at pressures of 500 Torr.

\subsubsection{Technical Approach to BB-CES}

The technical basis behind BB-CES lies in coupling the output of a mode-locked femtosecond (fsec) laser with the transmission properties of an optical sampling cavity. If the output "comb" of the modelocked fsec laser matches that the transmission "comb" of the optical cavity (or some harmonic of the mode spacing) then the laser light that is directed at the cavity will be transmitted. A spectrometer can then spectrally resolve this transmitted light to the desired resolution. The absorption spectrum of the sample can be obtained by taking the ratio of the spectrum of the sample in the cavity to the spectrum of the empty cavity (or possibly just of the laser itself). Figure 3.11 shows the basic layout of the technique along with a representation of coupling the output modes of a mode-locked fsec laser with a cavity and a simple simulation of how the actual data would appear.

Prior to attempting this new technique a straight forward signal-to-noise calculation was performed and outlined below. It is important to estimate the reduction in transmitted light through the cavity due to the presence of a molecular absorber The amount of light that is transmitted through the cavity at each resonance in the presence of a molecular absorber is given by,

$$
I_{\text {TRANS }}=I_{0}\left[\frac{1-R^{2}}{1-(\operatorname{Rexp}(-\sigma(v)[N] I))^{2}}\right]
$$

(normalized to unity in the absence of molecular absorption) where $\mathrm{R}$ is the mirror reflectivity, $\sigma(v)$ is the molecular absorption strength, $[\mathrm{N}]$ is the absorber concentration and 1 is the physical length of the cavity. For a situation where $\mathrm{R}=99.95 \%, 1=50 \mathrm{~cm},[\mathrm{~N}]$ is $1 \times 10^{10}$ molecular absorbers $/ \mathrm{cm}^{3}$ (approximately $1 \mathrm{ppb}_{\mathrm{v}}$ at $1 \mathrm{~atm})$, and $\sigma(v)$ is $10^{18} \mathrm{~cm}^{2}$ the resulting change in transmission would be $0.1 \%$. It is therefore required that the spectrometer on the output side of the cavity be capable of discerning a change in a 


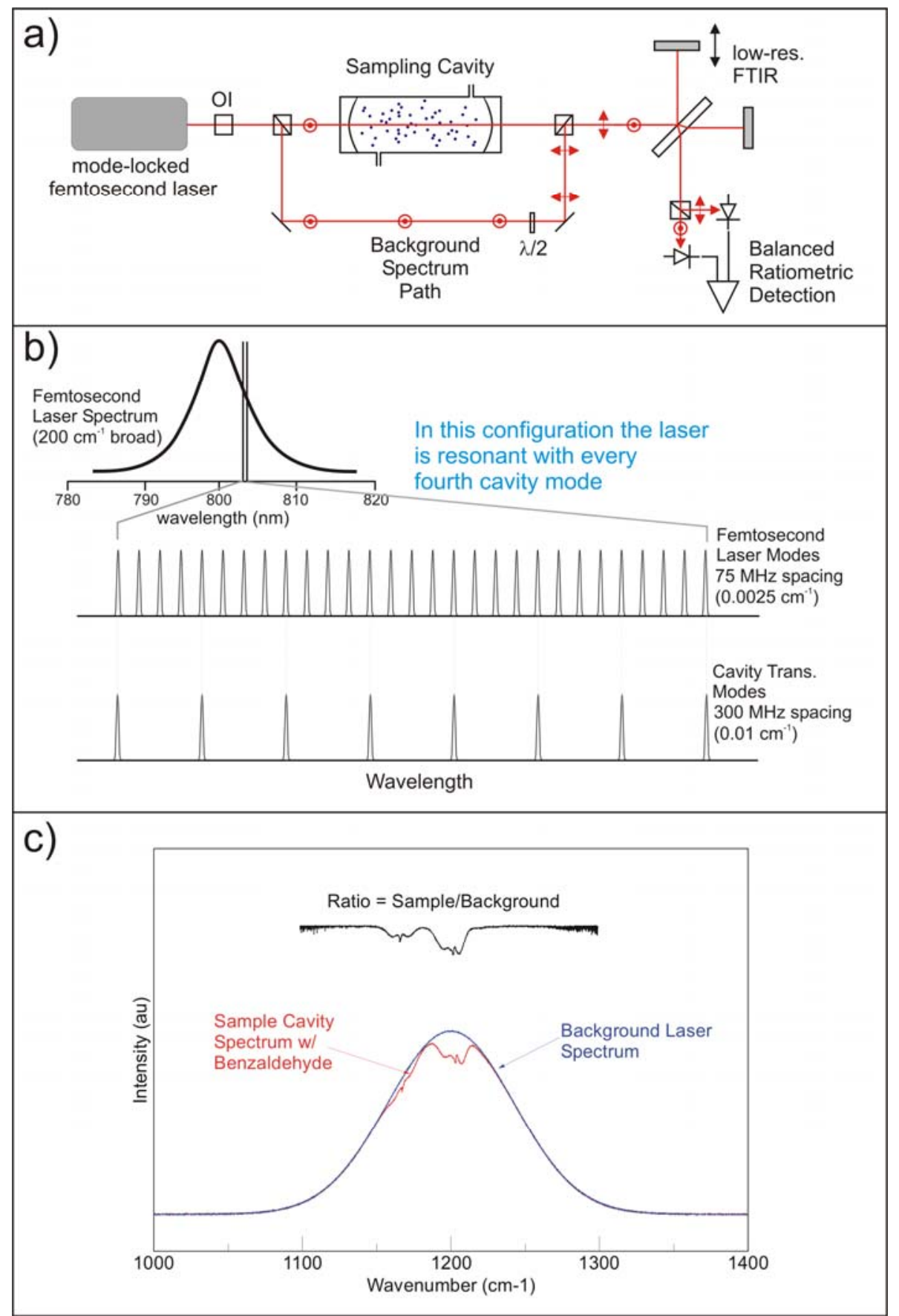

Figure 3.11. Broad band cavity enhanced sensing concept; a) depiction of the laser source, sampling cavity and spectrometer, b) schematic showing mode overlap between laser and cavity and c) simulated spectra of sample and empty cavity.

transmitted signal at this level or better which is quite achievable provided sufficient optical power reaches the spectrometer from the cavity. Calculating the absolute level of light transmitted through the cavity is more complex as it involves multiple factors that are difficult to estimate (e.g., mode coupling 
efficiency, etc.). However based on experience from the SWIR-CRDS instrument roughly $0.01 \%$ of the incident light is transmitted through the cavity. Assuming the mode-locked fsec laser produces 500 mWatts of average output power distributed into its $10^{5}$ longitudinal modes then each mode would have approximately $5 \mu \mathrm{W}$ of power (not including the Gaussian intensity distribution of the laser's output). Next the throughput of the optical cavity is factored in resulting in a $10^{4}$ reduction leaving $500 \mathrm{pW}$ in each mode. If the modes are spaced by $75 \mathrm{MHz}$ (or $0.0025 \mathrm{~cm}^{-1}$ ) and the spectral resolution of the spectrometer were $0.1 \mathrm{~cm}^{-1}$ then 40 laser modes would contribute to the signal-to-noise for each spectral resolution bin (i.e., $20 \mathrm{nW}$ ). Because of the coherent nature of this light it can be transmitted with high efficiency through a high-resolution spectrometer like a FTIR due to the fact that the light source is closely approximated by a point source rather than an extended source in most spectrometers (using thermal sources in the FTIR require a reduced aperture to obtain high spectral resolution, this aperture improves the coherence of the source but reduces the amount of photons). The spectrometer and detector losses could reduce the light detection efficiency by a factor of 10 to a value of $2 \mathrm{nW}$, which results in a $\mathrm{S} / \mathrm{N}$ of 100 for a typical near-infrared InGaAs detector with a Noise-equivalent-power of $0.2 \mathrm{pW} / \mathrm{Hz}^{1 / 2}, 10$ $\mathrm{kHz}$ bandwidth and $0.8 \mathrm{Amps} / \mathrm{Watt}$ responsivity. The $\mathrm{S} / \mathrm{N}$ would be reduced if not every laser mode were resonant with a cavity mode (like that shown in the figure above). This system would be able to discern the change of $0.1 \%$ in the transmitted signal for the $1 \mathrm{ppb}_{\mathrm{v}}$ detection described above.

Figure 3.12 shows the results from (Gheman 2004) in which an $800 \mathrm{~nm}$ titanium sapphire fsec laser is frequency doubled to the $400 \mathrm{~nm}$ and used to measure the weak overtone spectra of acetylene using the broad-band cavity enhanced spectrometer technique described here. The data shows the spectrum of an empty cavity, a cavity containing the absorbing sample and the resulting absorbance spectrum obtained via the ratio of the two spectra (plus another data reduction step described in Gheman 2004). To date there have been several examples of cavity enhanced spectrometers employing femtosecond mode-locked lasers as optical excitation sources, measuring several different molecular species.

\subsubsection{Initial Laboratory Measurements of BB-CES}

Our initial laboratory studies of BB-CES in FY05 were limited to testing coupling the output of a modelocked Ti:Sapphire femtosecond laser to a Fabry-Perot optical cavity. Fortunately a complete Ti:Sapphire laser system was available for these tests. Figure 3.13 is a photograph of the test apparatus showing both the lasers system and the linear open-path cavity setup on a long optical rail. The mode spacing of this laser system is $75.5 \mathrm{Mhz}$. This was confirmed by measuring the repetition rate of the pulsed output on a fast oscilloscope. The pulse duration was measured with an autocorrelator and was found to be < 200 fsec, with a spectral width of $8 \mathrm{~nm}$ centered at $800 \mathrm{~nm}$. One difficulty coupling any laser into a linear

Fabry-Perot cavity is the negative impact on the laser stability of back reflection off the front mirror of the cavity. In this case the back reflection caused the laser to drop out of mode locked operation. This was corrected with the use of two optical isolators (similar to what is used in PNNL's SWIR-CRDS instrument) providing over $50 \mathrm{~dB}$ of attenuation of back reflected intensity. Once the isolators were installed the cavity was co-aligned with the laser output. In order to confirm that the light from the laser was being properly coupled into and out of the cavity the cavity length was slightly dithered by $+/-1$ micron using a piezo-electric transducer will the absolute spacing between the mirrors was adjusted. 


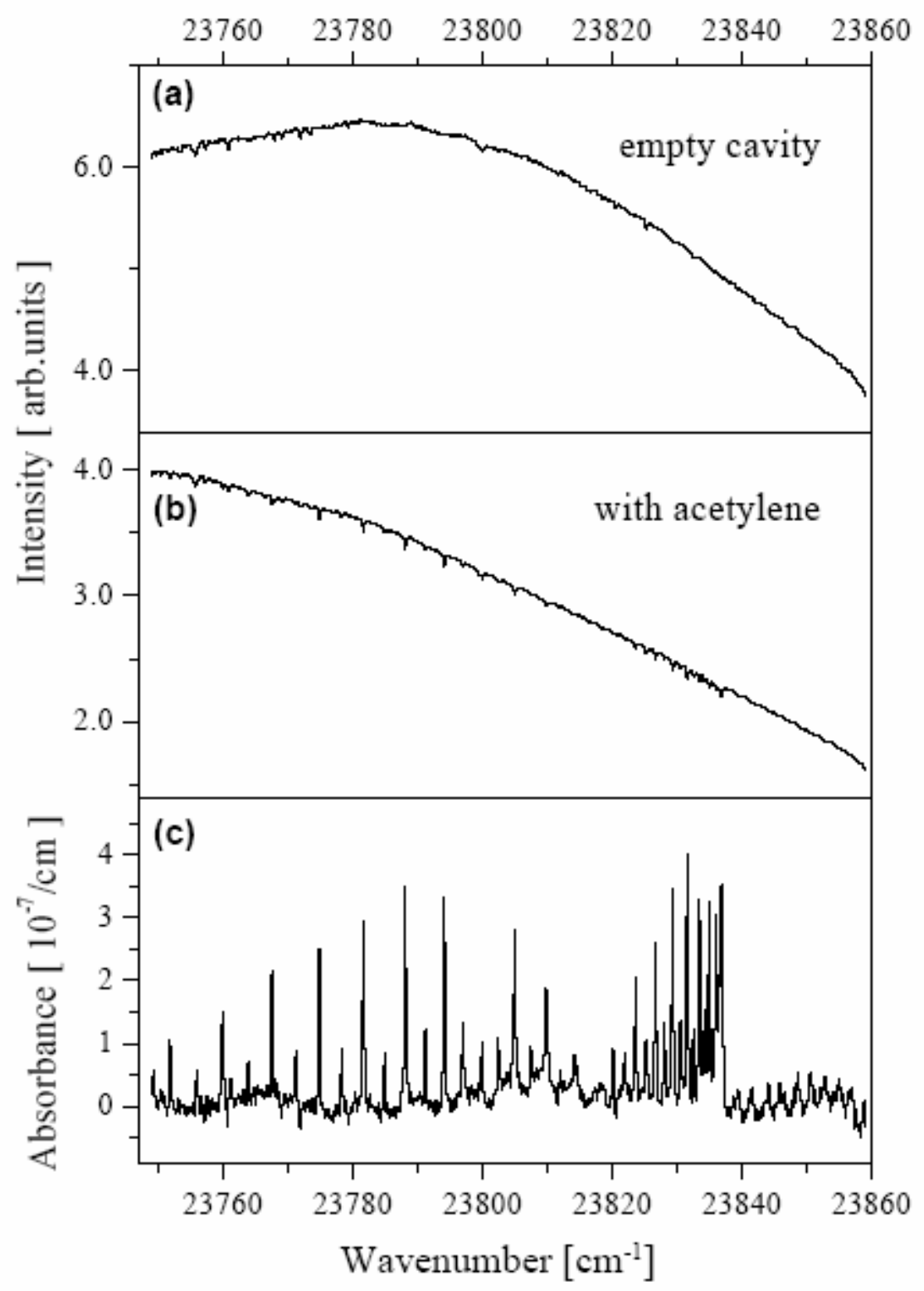

Figure 3.12. Taken from ref. (2) showing spectrum of fsec laser light transmitted through an empty cavity (a), a cavity with acetylene sample (b) and the resulting absorbance spectrum (c) computed from (a) and (b).

Once the absolute spacing of the cavity mirrors was set such that the cavity mode spacing was $151 \mathrm{MHz}$ (or twice that of the mode spacing of the fsec laser) a dramatic increase in the transmitted intensity was observed. This can be seen in Figure 3.14 in which a series of cavity scans is shown in which the absolute mirror spacing is adjusted away from the optimum spacing ( 0 microns of offset). As can be seen from the figure by the time the mirror separation is moved just 30 microns off of optimal the cavity transmission modes are essentially gone. This experiment demonstrated that the output of the mode- 


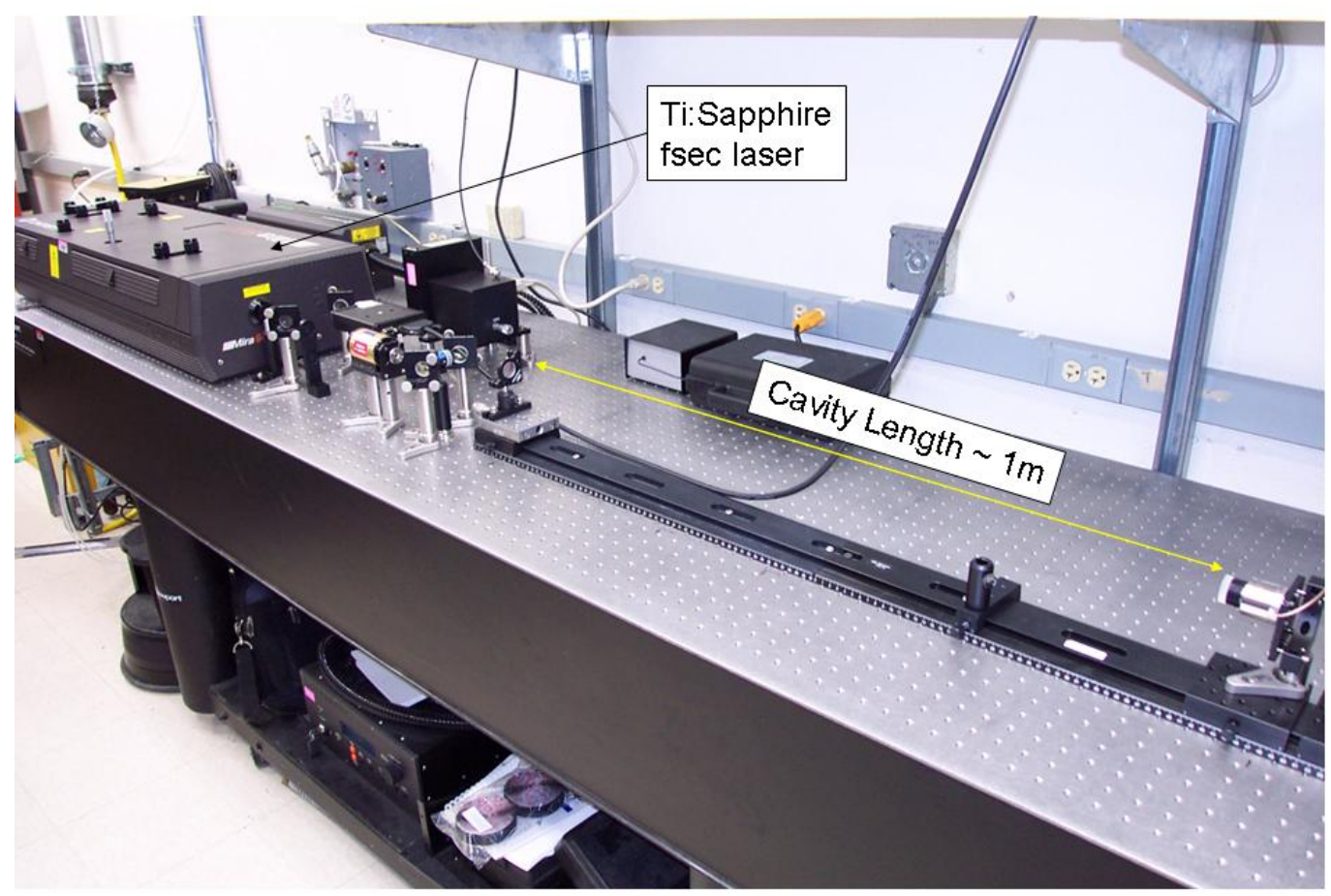

Figure 3.13. PNNL's BB-CES laboratory demonstration experiment. The cavity length is such that every other mode from the fsec laser is resonant.

locked Ti:sapphire fsec laser could be easily coupled through a standard high Finesse Fabry-Perot optical cavity; the first step toward demonstrating the detection of molecules with broadband infrared absorption features using this cavity enhanced technique. 


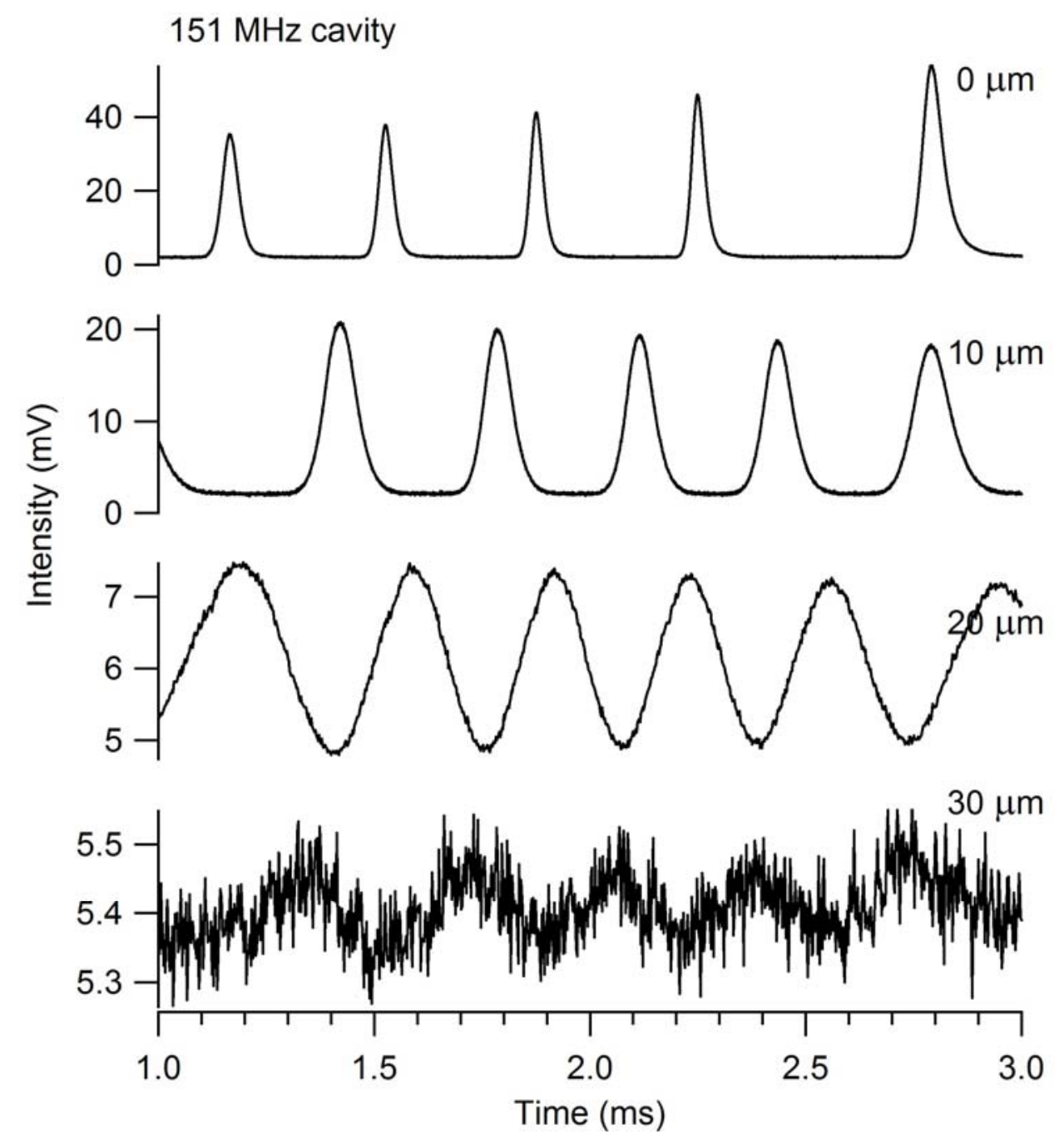

Figure 3.14. Cavity transmission spectra recorded as the absolute cavity length is adjusted away from the optimum for coupling to the output of a $75.5 \mathrm{MHz}$ mode-locked laser. 0 microns displacement corresponds to a fixed cavity length of $99.0 \mathrm{~cm}$. 



\subsection{Planned Work for FY06}

No further work on either the SWIR-CRDS or the BB-CES is planned under PNNL Project PL211I in FY06. A separate "new start" proposal (Proposal Number: PNNL-06-011) was submitted for FY06 titled, "In Situ Detection of $\underline{B}$ road- $\underline{B} a n d$ Molecular Absorbers using $\underline{\text { Cavity }}$ Enhanced $\underline{\text { Spectroscopy for }}$ the Monitoring of Uranium/Plutonium Separation Activities (BB-CES)." At the time of this writing the status of the proposal is "On Hold". 



\subsection{References}

Gheman T, S Kassi, A Campargue, and D Romanini 2004. "Overtone spectroscopy in the blue region by cavity-enhanced absorption spectroscopy with a mode-locked femtosecond laser: application to acetylene." Chemical Physics Letters 383,353-358.

Williams RM, WW Harper, PM Aker, JS Thompson, and TL Stewart. 2003. "Chemical Sensing Using Infrared Cavity Enhanced Spectroscopy: Short Wave Infrared Cavity Ring Down Spectroscopy (SWIR CRDS) Sensor." PNNL-14475, Pacific Northwest National Laboratory, Richland, WA.

Williams RM, JS Thompson, TL Stewart, and BJ Tweedy. 2004. "FY04 SWIR CRDS Summary Report.” PNNL-15248, Pacific Northwest National Laboratory, Richland, WA.

Williams GP 2005. “Shrike Campaign 2005: Test Report” Draft Version. 



\section{Distribution}

No. of

Copies

\section{OFFSITE}

LTC Ariel Cuadrado

United States DOE

NNSA/NA-22

1000 Independence Ave. SW

Washington, DC 20585

Dr. Rhys M. Williams

United States DOE

NNSA/NA-22

1000 Independence Ave. SW

Washington, DC 20585

Dr. David Berry

United States DOE

NNSA/NA-22

1000 Independence Ave. SW

Washington, DC 20585

Mr. Ralph Hastings

United States DOE

NNSA/NA-22

1000 Independence Ave. SW

Washington, DC 20585

Mr. Eric Sander

United States DOE

NNSA/NA-22

1000 Independence Ave. SW

Washington, DC 20585

Mr. W. Randy Bell

United States DOE

NNSA/NA-22

1000 Independence Ave. SW

Washington, DC 20585
No. of

Copies

Professor Henryk Temkin

Program Manager

DARPA/MTO

3701 N. Fairfax Dr.

Arlington, VA 22203-1714

\section{ONSITE}

\section{Pacific Northwest National Laboratory}

Bruckner-Lea, C K5-25

Clemmer, RG K8-29

Dudder, GB K8-29

Golovich, EC K5-25

Schultz, JF (5) K5-25

Sharpe, SW K8-88

Stewart, TL K5-25

Thompson, JS K5-25

Tweedy, BJ K5-25

Williams, RM K5-25

Information Release Office (7) K1-06 
